\title{
HARDWARE IN THE LOOP PARA FREIOS ABS HIDRÁULICO
}

\author{
Nouriandres Liborio Silva ${ }^{1}$, Armando A. M. Laganá ${ }^{1.2}$ e Kleber Nogueira Hodel ${ }^{1.3}$ \\ Universidade de São Paulo, Escola Politécnica, Departamento de Engenharia Elétrica, PSI \\ E-mails: nouriandres.liborio@usp.br, lagana@1si.usp.br, a.hodel@yahoo.com.br
}

\section{RESUMO}

O Hardware In The Loop (HIL) tornou-se uma técnica indispensável para o desenvolvimento de produtos no âmbito do modelo V, em particular para Unidades de Controle Eletrônico (ECUs) para veículos, sendo utilizado tanto na fase de desenvolvimento de modelos matemáticos como na fase de testes de integração, simulando um veículo completo. $\mathrm{O}$ desenvolvimento de HILs confiáveis que simulem com precisão sistemas reais ainda é um desafio para a engenharia de desenvolvimento, especialmente em complexos sistemas de segurança com sensores e atuadores inteligentes, como o sistema de frenagem ABS. O objetivo deste artigo é desenvolver um HIL para freio ABS hidráulico. Uma vez validado, pode ser usado para o desenvolvimento de um novo modelo matemático de freio ABS. O presente HIL consiste em componentes mecânicos e hidráulicos reais como cilindro mestre e servo-freio, transdutores de pressão, plataforma de simulação dinâmica do veículo, software de manipulação de dados, interface de entrada e saída e circuito de condicionamento de sinal. A simulação ocorre pela integração de partes reais e virtuais. A comparação ocorre entre os resultados dos dados simulados com e sem o controle do ABS. A validação do HIL ocorre pela comparação dos resultados dos dados.

\section{INTRODUÇÃO}

O avanço tecnológico das últimas décadas colocou de forma definitiva os sistemas eletrônicos no cotidiano da vida moderna, seja para um sistema veicular, bancário, de transporte, de saúde, de comunicação, de manufatura, entre tantos outros. Se de um lado tal inserção traz inúmeros benefícios às vidas das pessoas, de outro coloca novos desafios tecnológicos para a construção de sistemas computacionais mais confiáveis e seguros, sem os quais prejuízos e desastres tornar-se-ão inevitáveis.

Tratando-se do setor automobilístico, os veículos modernos estão cada vez mais equipados com sistemas eletrônicos que visam o conforto e, sobretudo a segurança de seus ocupantes. Os sistemas de segurança veiculares dividem-se em passivos, quando os sistemas atuam após a ocorrência de um acidente como, por exemplo, os sistemas de Air bags e os ativos, quando os sistemas atuam para evitar ou minimizar os impactos de um acidente como, por exemplo, os sistemas de freios ABS (Antilook Braking Systems).

O sistema de freio ABS é considerado um sistema complementar ao sistema de freio convencional de um veículo e tem como função principal evitar o travamento das rodas durante uma frenagem, pois caso essa intervenção não ocorra o condutor certamente perderá a 
dirigibilidade e até a estabilidade do veículo influenciando na sua distância de parada e aumentando drasticamente a chance da ocorrência de um acidente, sendo neste caso muito difícil prever suas consequências.

Sistemas de segurança ativa como os freios ABS demandam alta precisão e confiabilidade durante todo processo de desenvolvimento de seus componentes e principalmente na fase de testes de validação, quando o sistema ou a ECU (Electronic Control Unit) deve ser submetido a rigorosos testes com alto grau de severidade, em condições mais próximas possíveis da realidade, reproduzindo o que ocorre durante uma frenagem real de emergência solicitada pelo condutor.

Reproduzir condições reais de frenagens de emergência não tem sido uma tarefa fácil para a engenharia de desenvolvimento devido à exposição da equipe de testes a perigos que colocam em risco a vida de seus membros durante os severos testes em campo de provas, somado ainda ao alto custo desprendido com esses testes e ao tempo acrescido ao projeto no caso de erros serem identificados. Neste caso é necessário a repetição dos testes após as correções. Surge então a necessidade de encontrar métodos que auxiliem a engenharia no processo de desenvolvimento.

A metodologia conhecida como desenvolvimento baseado em modelo (Model Based Design, ou MBD) tem sido muito utilizada pela engenharia de desenvolvimento de softwares e tem se tornado cada vez mais popular nas indústrias automotivas. Segundo Santos e Neme [1], a principal característica deste método é o desenvolvimento em uma plataforma única, que permite a integração da planta do sistema e de seu controlador utilizando-se de uma mesma ferramenta computacional. Com isso a identificação e correção de erros ocorrem de maneira integrada ao desenvolvimento.

A metodologia MBD contém em seu processo de desenvolvimento os testes de validação. Dentre esses testes está a simulação HIL (Hardware In the Loop), a qual é utilizada para realização de simulações em tempo real, dentro das quais se incluem modelos matemáticos que representam o processo ou a planta controlada, assim como, um componente real para o qual se deseja realizar a validação. Segundo Aguinaldo [2], as validações através do uso de HIL e softwares de simulação veicular permitem que grande parte dos testes necessários sejam executados em bancada, eliminando-se, por exemplo, a necessidade de coleta de dados em campos de prova e subsequente correção de algoritmos de controle.

A simulação HIL não está restrita a indústria automobilística. Outros segmentos industriais se beneficiam desta plataforma. De acordo com Halvoersen [3], o HIL teve suas raízes na aviação e a razão pela qual o uso desse processo está se tornando mais prevalente em todos os setores é impulsionado por dois fatores principais: tempo de comercialização e complexidade. Halvoersen completa que a métrica de eficiência de desenvolvimento e teste é tipicamente uma fórmula que inclui os seguintes fatores: Custo, Duração e Segurança.

\section{OBJETIVO}

O objetivo deste trabalho é desenvolver uma plataforma Hardware In the Loop para freios ABS hidráulico. 


\section{DESENVOLVIMENTO BASEADO EM MODELOS - MBD}

O avanço tecnológico do setor automobilístico nas últimas décadas demandou grande necessidade de veículos com sistemas eletrônicos inteligentes capazes de prover conforto e segurança aos seus ocupantes. O número de ECU's crescem exponencialmente a cada veículo lançado e cada vez mais os sistemas estão integrados uns aos outros. Devido à falta de espaço alguns hardwares contêm mais de uma ECU, são as chamadas ECU's virtuais. Com isso o nível de complexidade para desenvolvimento também aumenta.

Estudos preveem que dentre as futuras inovações em sistemas veiculares, $90 \%$ serão baseadas no desenvolvimento de sistemas eletrônicos e softwares embarcados [4]. Veículos de luxo chegam a ter softwares com mais linhas de códigos do que jatos modernos a aviões comerciais [5]. Neste contexto, ressalta-se a importância das atividades de testes de validação dentro do processo de desenvolvimento de ECU's com métodos eficazes que contemplem os fatores como: custo, tempo e segurança conforme já descritos anteriormente.

A metodologia MBD, também conhecida como ciclo de processo de desenvolvimento em forma de $\mathrm{V}$, tem sido largamente aplicada pela engenharia de desenvolvimento e mostrando sua eficácia durante todas as fases do processo.

O MBD é compreendido como um ciclo de desenvolvimento sequencial que segue etapas de testes bem definidas em cada fase do processo. $\mathrm{O}$ modelo $\mathrm{V}$ divide o processo de desenvolvimento de software em duas fases principais. O lado esquerdo do V é a parte da análise de requisitos, design de função / software e gerenciamento de mudanças. O lado direito do $\mathrm{V}$ concentra as principais atividades de verificação e validação. A figura 1 apresenta os aspectos essenciais da metodologia MBD com seu ciclo V [6][1] :

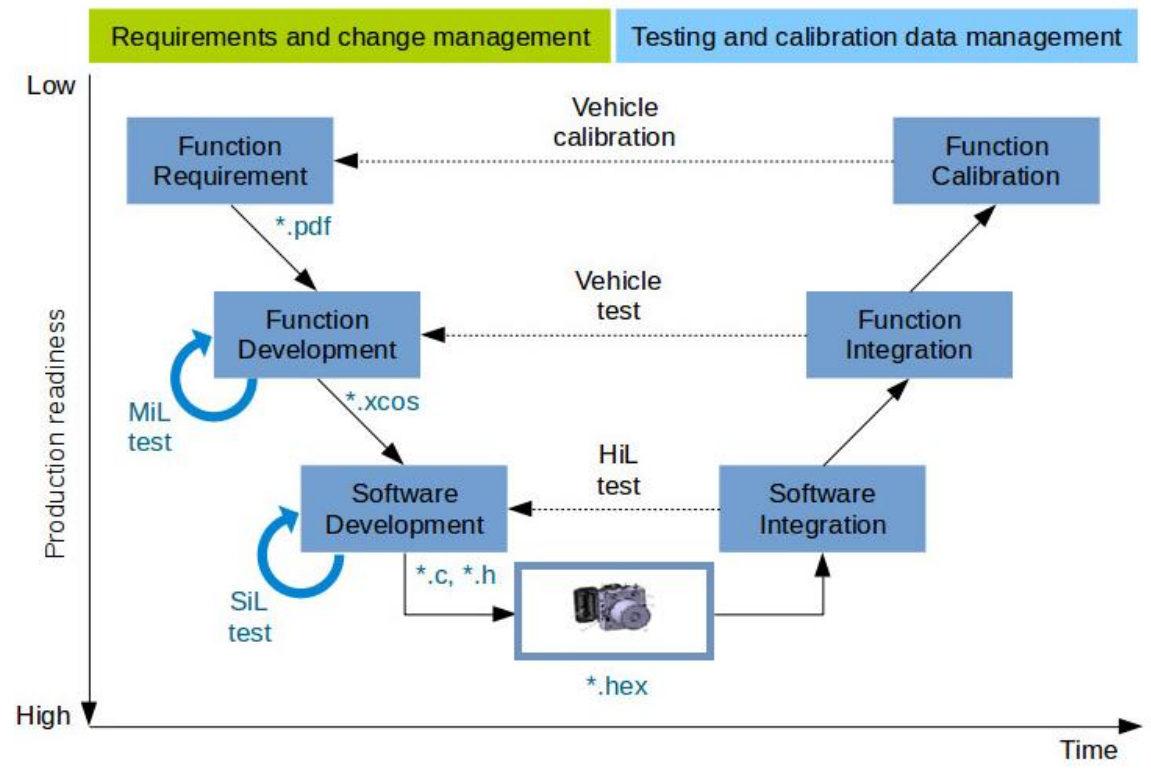

FIGURA 1. Desenvolvimento baseado em modelo

FONTE: Adaptado de Google imagens. Disponível em <https://x-engineer.org> Acesso em 05 de maio de 2018

Os aspectos essenciais do processo de desenvolvimento de software do ciclo V são [6]: 
- Requisitos de Função: O processo começa com a análise dos requisitos da função. Este é um passo muito importante porque define o que é esperado do software de controle em termos de funcionalidade. Os requisitos de função descrevem o que o software deve fazer do ponto de vista funcional.

- Desenvolvimento de Função: Uma vez que os requisitos de função estejam claramente definidos e acordados entre a engenharia de desenvolvimento e a engenharia de requisitos/sistemas, o desenvolvimento da função pode ser iniciado. A função de controle é desenvolvida como um diagrama de blocos que tem a capacidade de ser simulada e destaca possíveis erros do projeto. Depois que o design da função estiver concluído, a função é submetida a uma série de testes. Esses testes são chamados de testes Model in the Loop (MiL), pois estão usando modelos (diagramas de blocos) para simular a funcionalidade necessária.

- Desenvolvimento de software: o modelo é substituído pelo código fonte e o software base que será utilizado na ECU. Nesta etapa o modelo da planta e o software são testados em uma mesma máquina. Nesta fase de desenvolvimento, há mais detalhes sobre a funcionalidade. Processos modernos de desenvolvimento de software estão utilizando ferramentas de projeto baseadas em modelos, com capacidades automáticas de geração de código. Com esses modernos processos, torna-se possível executar o Software in the Loop (SiL). Ao fazer testes de SiL, pode-se verificar se o software está fornecendo a funcionalidade necessária (em comparação com o modelo).

- Integração de software: A integração de software é o processo de combinar todos os módulos de software necessários para um projeto específico. O software é embarcado no módulo eletrônico e o teste é realizado através da simulação HIL. Nesta etapa a ECU é conectada a um ambiente de simulação em tempo real que simula a planta controlada. Esta etapa será detalhada no tópico 2.1 por ser o alvo deste artigo.

- Integração de funções: Na etapa final a ECU é conectada ao veículo e os testes de validação são realizados no sistema integrado e não mais no componente somente. $\mathrm{O}$ objetivo é testar a função desenvolvida no nível do veículo (modelo de produção ou um protótipo). A finalidade do teste do veículo é validar a implementação correta dos requisitos e a integração com os outros módulos de controle

- Calibração de funções: O último passo no desenvolvimento de software é a calibração de funções. A maioria das funções de controle de software são genéricas, elas são adequadas para diferentes aplicações de veículos (variantes). A etapa de calibração de funções define os parâmetros corretos para as funções do software.

A etapa de integração de software, que trata dos testes de simulação HIL, será detalhada neste próximo tópico separadamente ressaltando a importância dessa ferramenta para a engenharia de desenvolvimento, tornando-se atualmente parte indispensável do método MBD.

\subsection{Simulação através de Hardware In the Loop}

O processo HIL existe há pouco mais de 20 anos, tendo surgido primeiramente na indústria da aviação. A simulação HIL é uma técnica usada no desenvolvimento e teste de sistemas de processos complexos e fornece uma plataforma eficaz, 
adicionando a complexidade da planta sob controle à plataforma de teste. A complexidade da planta sob controle está incluída no teste e desenvolvimento, adicionando uma representação matemática de todos os sistemas dinâmicos relacionados. Essas representações matemáticas são chamadas de "simulação da planta"[3].

A simulação HIL pode ser definida como uma técnica na qual um sistema em malha fechada é emulado através do uso de componentes reais e simulado. A simulação HIL tem como objetivo principal testar o dispositivo antes de implementá-lo na planta real.

A simulação HIL tornou-se indispensável para as indústrias aeroespacial, automotiva, marítima e de defesa. Uma considerável indústria global de HIL apoia essas atividades de desenvolvimento e as universidades estão integrando rapidamente a simulação HIL em seus currículos. Esta crescente prevalência de simulação HIL atesta suas muitas vantagens, incluindo [7]:

- Custo-efetividade: a simulação de HIL geralmente requer um hardware significativamente menor do que a prototipagem física, o que custa menos.

- Prototipagem rápida: Como eles geralmente exigem menos hardware do que protótipos totalmente físicos, os simuladores HIL também podem ser consideravelmente mais rápidos de construir.

- Velocidade de simulação: as simulações HIL de fenômenos físicos complexos são executadas mais rapidamente do que simulações virtuais dos mesmos fenômenos (por exemplo, simulações de motores IC baseadas em dinâmica computacional de fluidos).

- Abrangência: A simulação de HIL muitas vezes torna possível simular um determinado sistema em uma faixa muito mais ampla de condições de operação do que o que é viável por meio de protótipos puramente físicos.

- Segurança: Outro benefício do HIL é que o teste pode ser feito sem danificar o equipamento ou colocar em risco vidas. Por exemplo, testes de freios ABS em extremos de desempenho. Se simulado, o desempenho do sistema ABS pode ser avaliado sem risco para o veículo ou operador.

- Podem-se testar partes diferentes do sistema individualmente para garantir que ele funcione como planejado e a simulação HIL é importante no projeto e no teste dos diferentes sistemas.

- Confiabilidade: Se o modelo matemático usado no simulador for uma representação precisa do processo real, pode-se até calibrar os parâmetros do controlador (por exemplo, os parâmetros do PID) usando o simulador.

- Também é muito útil para fins de treinamento, ou seja, o operador de processo pode aprender como o sistema funciona e opera usando a simulação de hardware em loop.

- Engenharia de sistemas simultâneos: Finalmente, a simulação de HIL permite que diferentes equipes desenvolvam diferentes partes de um sistema em hardware sem perder de vista problemas de integração, permitindo assim a engenharia simultânea de sistemas.

A figura 2 apresenta o princípio básico de operação de um sistema HIL. Utilizando-se de um computador de simulação, as informações de entrada necessárias ao sistema 
testado são geradas pelo modelo da planta e enviadas a um simulador de sensores. Este tem a função de emular características elétricas dos sensores e transformar as informações em sinais que são interpretados pelo sistema em teste.

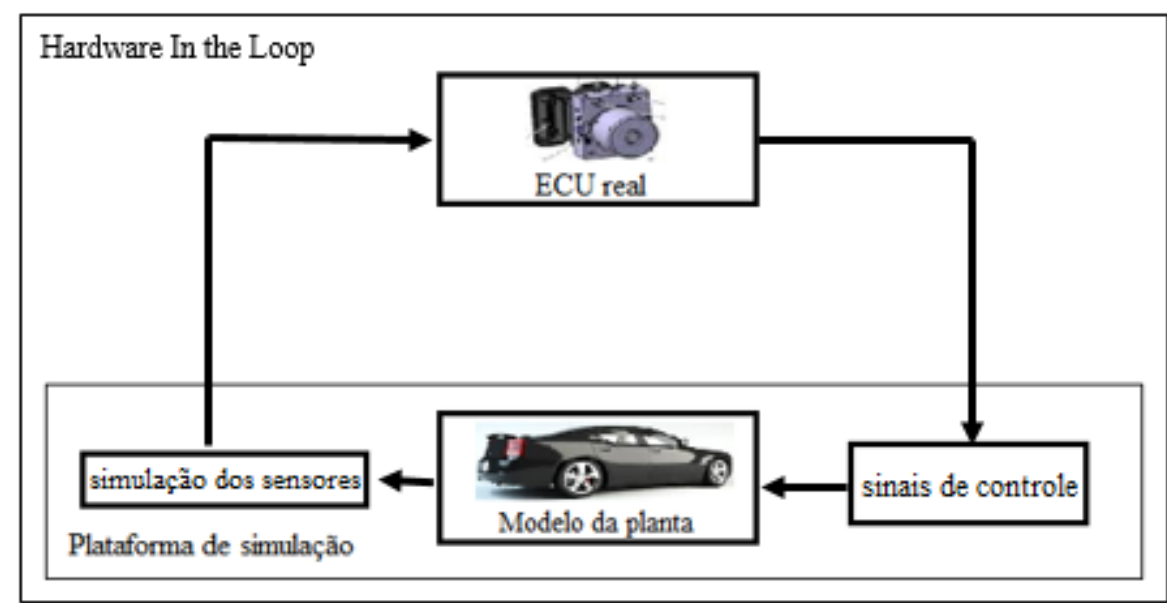

FIGURA 2. Princípio básico de operação de um sistema HIL FONTE: O Próprio autor

A emulação de todos os sinais elétricos necessários para o pleno funcionamento da ECU e a execução em tempo real do modelo virtual da planta são pré-requisitos para que a simulação HIL seja executada com sucesso. Caso a emulação de sinais não seja completamente atendida, o módulo eletrônico pode não efetuar o processamento das informações, pois entende que se encontra em condição de falha [2].

Após o processamento, os sinais de resposta do sistema testado são adquiridos e realimentados ao modelo da planta, formando um sistema em malha fechada. O HIL é uma forma de simulação em tempo real.

\section{METODOLOGIA DE PESQUISA}

Esta seção apresenta o método experimental através da simulação HIL. A Tabela 1 mostra as peças de hardware e software usadas no experimento bem como suas respectivas funções.

Tabela 1. Componentes utilizados na plataforma desenvolvida e respectivas funções

\begin{tabular}{|l|l|c|}
\hline Componente & Função & Identificação \\
\hline ECU ABS Hidráulico & Sistema testato & 1 \\
\hline Alavanca de acionamento & Simular acionamento do pedal & 2 \\
\hline Servo-freio & Multiplicador da força pedal & 3 \\
\hline Cilindro mestre & Distribuição da pressão hidráulica para a ECU & 4 \\
\hline Transdutores de pressão & Fornecer os sinais de controle da pressão & 5 \\
\hline Circuito elétrico & Condicionamento dos sinais de entrada e saida & 6 \\
\hline Interface de entrada e saida & Conversão dos sinais analogicos em sinais digitais & 7 \\
\hline \multirow{5}{*}{ Interface de diagnose OBD } & Leitura de falhas & \multirow{2}{*}{8} \\
\hline \multirow{5}{*}{ Computador de simulação } & Modelo matemático do veiculo & \multirow{2}{*}{9} \\
\cline { 2 - 2 } & Interface com o modelo matemático do veiculo \\
\cline { 2 - 2 } & Cálculo das frequências dos sinais dos sensores \\
\cline { 2 - 2 } & Cálculo da variação de pressão nos cilindros de freio & \\
\cline { 2 - 2 } & Software para diagnose & \multirow{2}{*}{10} \\
\hline \multirow{2}{*}{ Bomba de vácuo } & Criar depressão para o servo-freio \\
\hline
\end{tabular}


As figuras 3 e 4 ilustram a arquitetura física e a montagem real do sistema proposto:

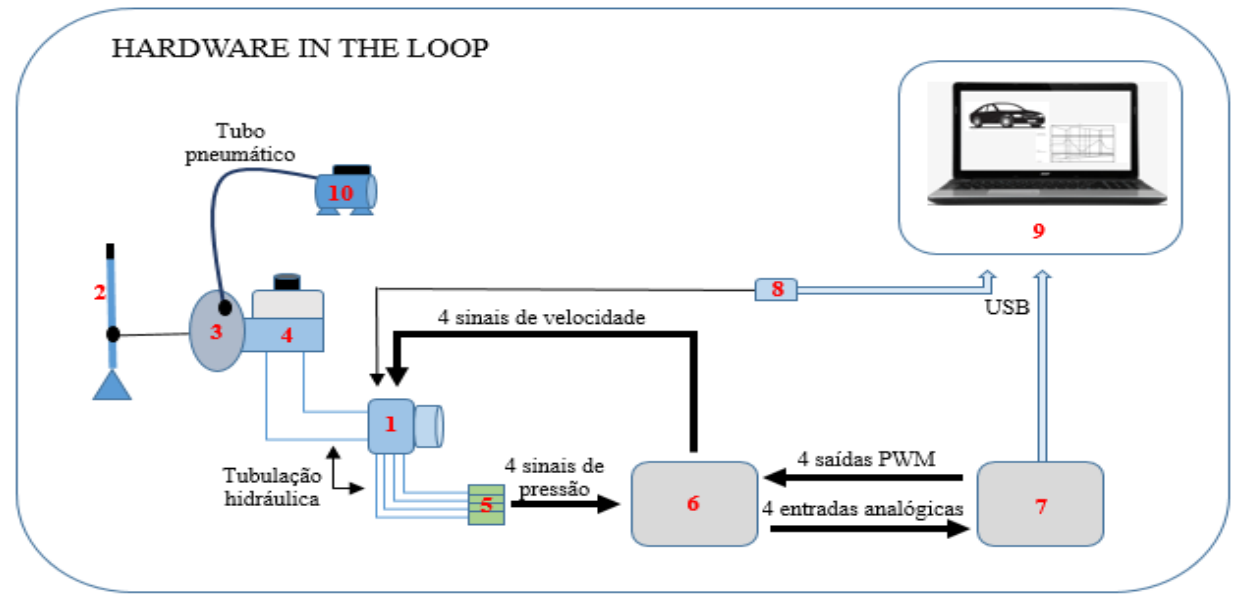

FIGURA 3. Arquitetura da plataforma HIL desenvolvida FONTE: O próprio autor

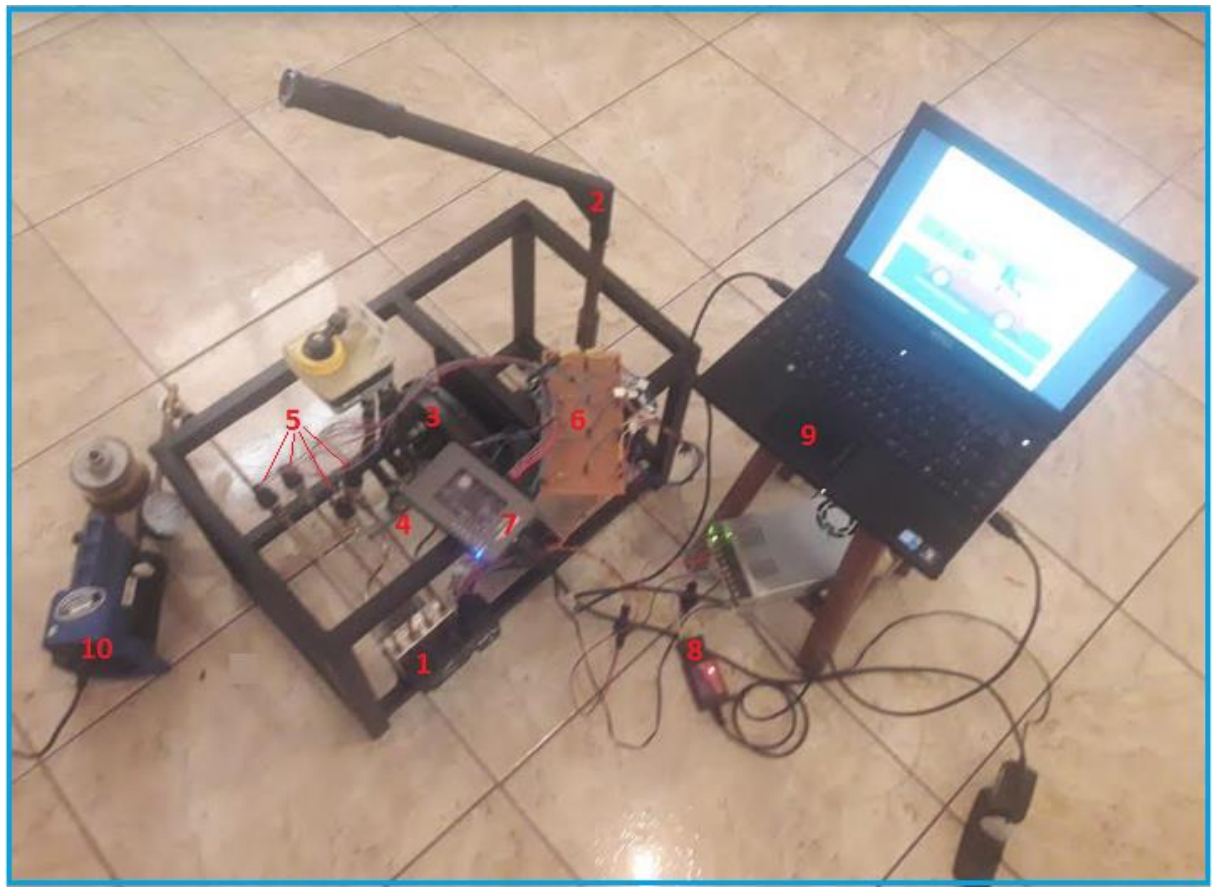

FIGURA 4. Imagem real da plataforma HIL desenvolvida FONTE: O próprio autor

Na subseção 3.1 são apresentados a implementação detalhada da simulação HIL.

\subsection{ECU para freios ABS hidráulico}

A ECU para freios ABS hidráulico é composta pela integração da parte eletrônica com a parte hidráulica. A parte eletrônica é composta pelos circuitos eletrônicos e de potência bem como o software embarcado com o sistema de controle. Os circuitos de potência são responsáveis pelo acionamento das válvulas e da bomba responsável pelo alivio da pressão hidráulica. A parte hidráulica é composta pelo corpo 
hidráulico onde estão os dutos de passagem do fluido e os pinos das válvulas responsáveis pela abertura ou fechamento da passagem do fluido.

A ECU do ABS hidráulico tem como função monitorar, manter e até reduzir a pressão das rodas de acordo com a demanda do sistema. A única informação recebida pela ECU é a velocidade de cada roda individualmente, a qual é mais do que suficiente para o sistema atuar. Em caso de falhas, a ECU entra em modo inoperante e o sistema convencional do freio continua funcionando normalmente. As válvulas solenoides estão instaladas na parte interna da ECU. São oito válvulas ao todo sendo duas para cada roda: uma normal aberta outra normal fechada.

Durante a fase de monitoramento a ECU apenas recebe a informação de velocidade das rodas através dos sensores e as compara. Quando uma das rodas tende ao travamento, a válvula normal aberta se fecha, mantendo constante a pressão naquele circuito hidráulico. A fase de redução de pressão entra em operação quando a roda em questão está na iminência de travamento, então a válvula normal fechada se abre e a bomba elétrica aciona aliviando a pressão daquele circuito.

As modernas ECU's para freios hidráulicos são capazes de integrar ainda outros sistemas como, por exemplo, o de monitoramento da pressão dos freios através da diferença de rotação entre as rodas e até sistemas de controle de estabilidade.

Os sensores de velocidade utilizados na ECU apresentada neste artigo são do tipo magneto-resistivo. Esses sensores trabalham com comutação de corrente através da aproximação ou afastamento dos espaçamentos contidos no anel magnético preso ao rolamento da roda onde o sensor está posicionado. A alimentação dos sensores é fornecida pela própria ECU. São fornecidos $12 \mathrm{~V}$ e a comutação ocorre pelo sinal negativo.

\subsection{Geração da pressão hidráulica}

Para que exista variação de pressão na saída da ECU do ABS e esta seja coletada nos transdutores é necessário gerar fisicamente essa pressão. Para atender essa necessidade foi construída a parte mecânica do HIL. Essa parte mecânica é composta primeiramente pela alavanca de acionamento que recebe a força humana para início da geração da pressão. A força aplicada na alavanca é multiplicada pelo servo-freio que está fisicamente conectado a alavanca e pneumaticamente conectada a bomba de vácuo. Essa força finalmente chega ao cilindro mestre onde está o fluido hidráulico.

O cilindro mestre recebe a força mecânica na entrada e a distribui para o sistema em forma de pressão hidráulica via fluido e conexões hidráulicas. A pressão hidráulica passa pelo corpo hidráulico da ECU do ABS e chega até os tradutores de pressão. Finalmente a combinação mecânica hidráulica está pronta para ser controlada pelo sistema eletrônico.

\subsection{Circuito elétrico condicionador de sinais}

Para que a ECU identificasse os sinais de entrada de velocidade foi necessário criar um circuito elétrico condicionador de sinais. 
Para os sinais de entrada da ECU foram utilizados 4 transistores NPN, 4 capacitores de $1 \mu \mathrm{F}, 4$ resistores de $33 \mathrm{k} \Omega, 4$ de $860 \Omega$ e 4 de $20 \Omega$. A figura 4 apresenta a conexão entre a interface de entrada e saída para uma roda e a ECU ABS. O circuito completo é composto por 4 circuitos idênticos ao da figura 5 .

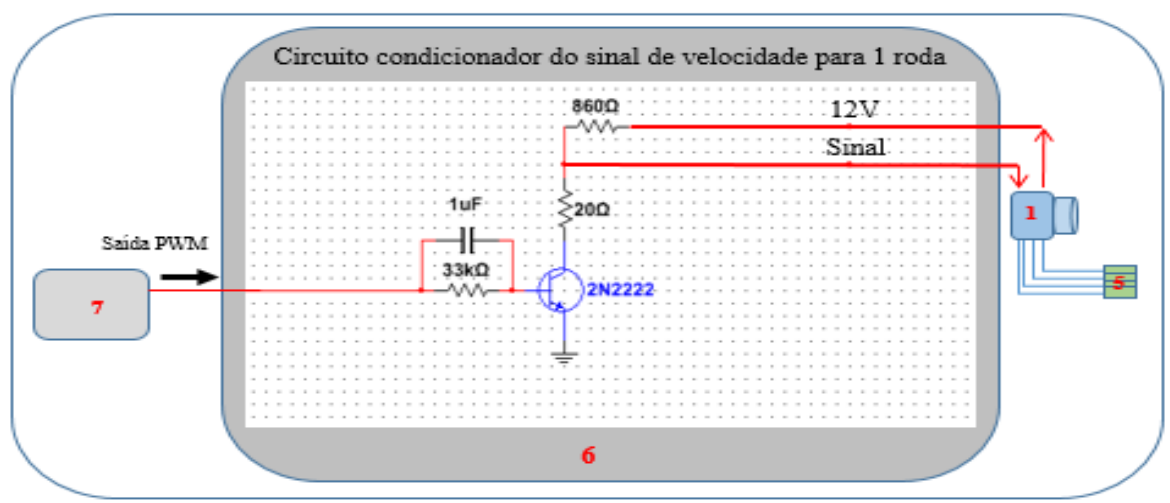

FIGURA 5. Circuito condicionador do sinal do sensor de velocidade simulado FONTE: O próprio autor

A ECU do ABS alimenta o sensor com $12 \mathrm{~V}$ e recebe um sinal de corrente de aproximadamente $14 \mathrm{~mA}$ como sinal alto. Um sinal PWM de $50 \%$ é fornecido como entrada de frequência para realizar o chaveamento do transistor. O transistor quando chaveado permite que aproximadamente metade da corrente siga em direção ao aterramento, fazendo com que a ECU receba aproximadamente $7 \mathrm{~mA}$ que é por ela identificado como sinal baixo.

Como a parte eletrônica da ECU está integrada a parte hidráulica, o acesso às válvulas não é possível. Para identificar o estado das válvulas e consequentemente a atuação da ECU foi necessário fazê-lo de forma indireta, ou seja, utilizou-se transdutores de pressão nas saídas hidráulicas da ECU e capturou-se a variação do sinal através da variação de pressão do sistema. A figura 6 apresenta o circuito utilizado para o sinal de pressão referente a uma roda.

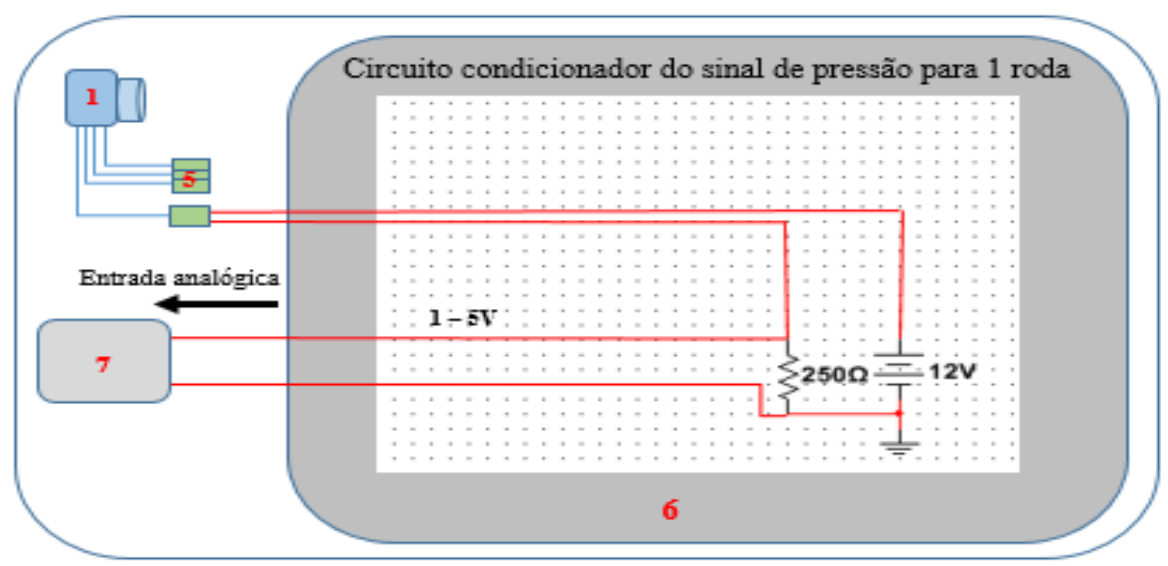

FIGURA 6. Circuito condicionador do sinal do sensor de pressão FONTE: O próprio autor 
Como o transdutor de pressão opera com variação de corrente de 4 a $20 \mathrm{~mA}$, foi necessário adicionar um resistor de $250 \Omega$ como shunt. Ao alimentar o transdutor de pressão com $12 \mathrm{~V}$ torna-se possível capturar a variação de pressão através da variação de tensão que fica entre 1 e $5 \mathrm{~V}$. O circuito completo é composto por 4 circuitos idênticos ao da figura 6 .

\subsection{Interface de entradas e saídas}

Foram utilizadas 4 saídas PWM disponíveis na interface de entradas e saídas reconfiguráveis para gerar os sinais dos sensores de velocidade das rodas.

A identificação do estado de cada uma das válvulas moduladoras de pressão foi realizada de forma indireta através da captura dos sinais de tensão dos transdutores de pressão através de 4 entradas analógicas.

\subsection{Plataforma de simulação dinâmica do veículo}

A Plataforma de simulação é composta por hardware e software. O hardware compreende um computador desktop ou notebook com capacidade para suportar softwares de simulação. Aconselha-se que tenha memória RAM não inferior a 8GB e processador não inferior a $1.8 \mathrm{GHz}$. Os softwares para a simulação serão descritos nas subseções a seguir.

\subsubsection{Software de simulação da dinâmica veicular}

O software de dinâmica veicular utilizado neste experimento contém modelos matemáticos de veículos de passeio, vans e pick-ups, possibilitando a aplicação de diversos modelos bem como a alteração dos parâmetros de um modelo em particular, como por exemplo, alterar as medidas dos pneus e executar um teste de frenagem possibilitando a comparação dos resultados.

Neste contexto, é possível também realizar testes em diferentes ambientes de simulação como por exemplo pista molhada, asfalto ou pista não pavimentada. A simulação HIL em questão opera com sistemas em tempo real, portanto qualquer software de dinâmica veicular que satisfaça essa exigência pode ser aplicado nesta plataforma.

Existem softwares de dinâmica veicular com versões temporárias gratuitas, como por exemplo: DYNA4 (da Tesis Dynaware), CarMarker (da IPG automotive), Carsim (da Mechanical Simulation), Virtual Car (apresentado em [8]) dentre outros, que podem ser utilizados em experimentos como o aqui apresentado.

\subsubsection{Interface com modelo matemático do veículo}

A interface com o modelo matemático do veículo foi realizado utilizando o mesmo conceito que Aguinaldo [2], ou seja, através da implementação de uma DLL (Dynamic-link library ou biblioteca de vínculo dinâmico) que permite a seleção e importação ou exportação de variáveis. 


\subsubsection{Cálculo da frequência do sinal dos sensores}

A ECU do freio ABS hidráulico, conforme descrito anteriormente, interpreta a velocidade das rodas através de sinais de nível baixo e alto comutados pelos sensores instalados próximos aos rolamentos das rodas. Os sensores de velocidade das rodas são do tipo ativo. São sensores magneto resistivos e trabalham com comutação de corrente de aproximadamente $7 \mathrm{~mA}$ e $14 \mathrm{~mA}$ para os sinais nível baixo e alto respectivamente. Esse sinal de corrente é recebido pela ECU através de um resistor interno de $75 \Omega$.

Com essa informação, torna-se possível ler os sinais dos sensores de velocidade das rodas com um osciloscópio e entender a forma do sinal. Os sensores de velocidade geram sinal de onda quadrada de aproximadamente $0.5 \mathrm{~V}$ no nível baixo e aproximadamente $1.2 \mathrm{~V}$ no nível alto. A variação da velocidade é diretamente proporcional à variação de frequência. Para o cálculo de frequência aplicou-se a fórmula descrita em [9]:

$$
v_{v}=\frac{o_{v}}{N} \cdot f_{s}
$$

Nela $v v$ representa a velocidade de uma roda, $0 v$ o perímetro do pneu, $N$ o número de dentes do anel dentado utilizado na roda e $f s$ a frequência do sinal. A figura 7 apresenta o sensor magneto resistivo e sua forma de onda gerada.

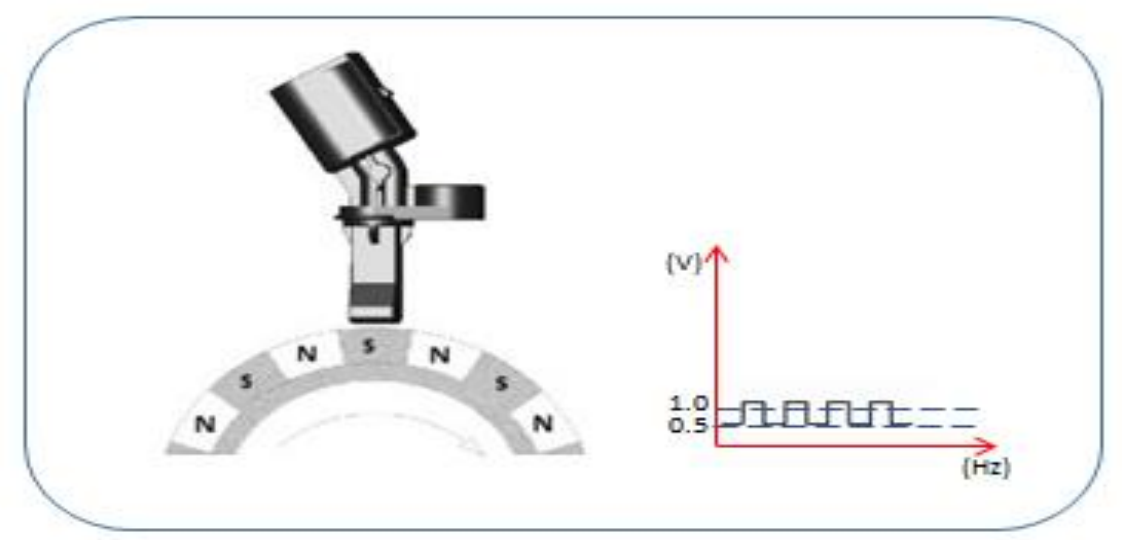

FIGURA 7. Sensor magneto resistivo e forma de onda

FONTE: FAE. Wheel Speed Sensors - ABS adaptado de:

< http://www.fae.es/en/products/wheel-speed-sensor-abs> Acessado em 04 de Maio de 2018

\subsubsection{Software para diagnose}

A diagnose da ECU do ABS foi realizada através da k-line disponível no pino 2 do módulo. A linha $\mathrm{K}$ é a que fornece informação em uma forma digital serial, a partir do módulo eletrônico até o equipamento de diagnóstico e geralmente está disponível no conector OBD do veículo.

O software de diagnose utilizado nesta plataforma foi baixado da internet. Existem na internet diversos softwares e aplicativos de diagnose com versões 
gratuitas para download e que são capazes de efetuar leitura de sinais dos sensores e até apagar falhas.

Foi utilizado um hardware de interface baseado em um circuito integrado da família ELM para a leitura do protocolo ISO 9141, o qual normaliza a linha K.

\section{ANALISE DOS RESULTADOS}

Para a realização do teste de simulação utilizou-se as características de um veículo pick-up cabine simples com as seguintes características:

- Pneus 205/70R15

- Entre eixos $2.753 \mathrm{~mm}$

- Peso do veículo em ordem de marcha $1.168 \mathrm{~kg}$

A seguir são apresentados os resultados:

4.1. Teste de frenagem de $100 \mathrm{~km} / \mathrm{h}$ a $0 \mathrm{~km} / \mathrm{h}$ em pista com coeficiente de atrito de 0,5 com acionamento utilizando a ECU ABS

Nas figuras 8 e 9 são apresentados os gráficos com os resultados da frenagem de 100 $\mathrm{km} / \mathrm{h}$ até $0 \mathrm{~km} / \mathrm{h}$ com coeficiente de atrito de 0,5 para os eixos dianteiro e traseiro. Nas legendas das figuras a seguir, as rodas são descritas pelas letras L (left) e R (right) para os lados esquerdo e direito respectivamente. $\mathrm{O}$ eixo frontal é descrito como primeiro eixo ou eixo de número 1 e o eixo traseiro como segundo eixo ou eixo 2. Neles é possível perceber que o controle realizado pela ECU ABS evita o travamento das rodas durante a frenagem, mantendo a estabilidade e a dirigibilidade do veículo.

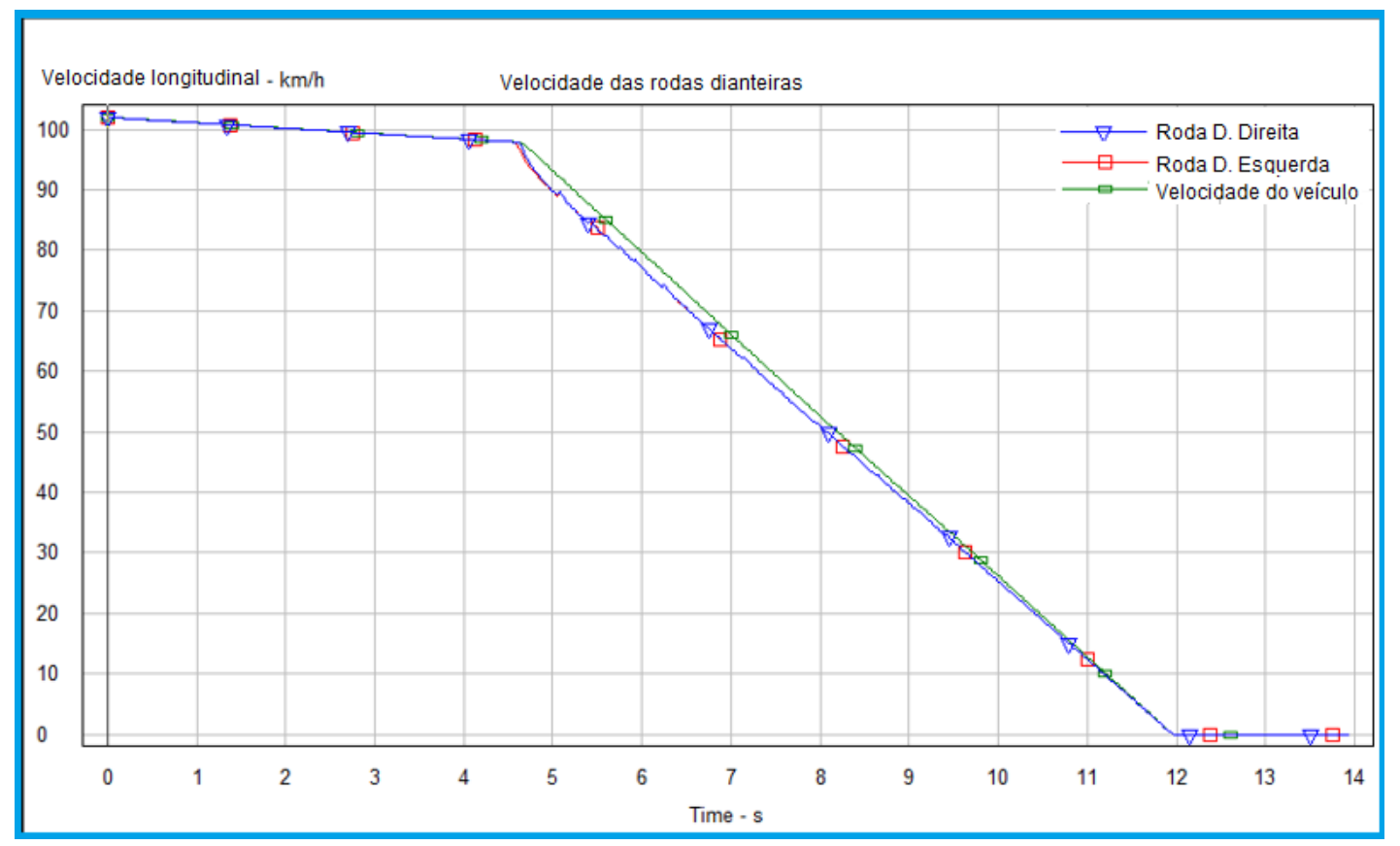

FIGURA 8. Velocidades das rodas do eixo dianteiro e velocidade de referência do veículo

FONTE: Software de simulação veicular 


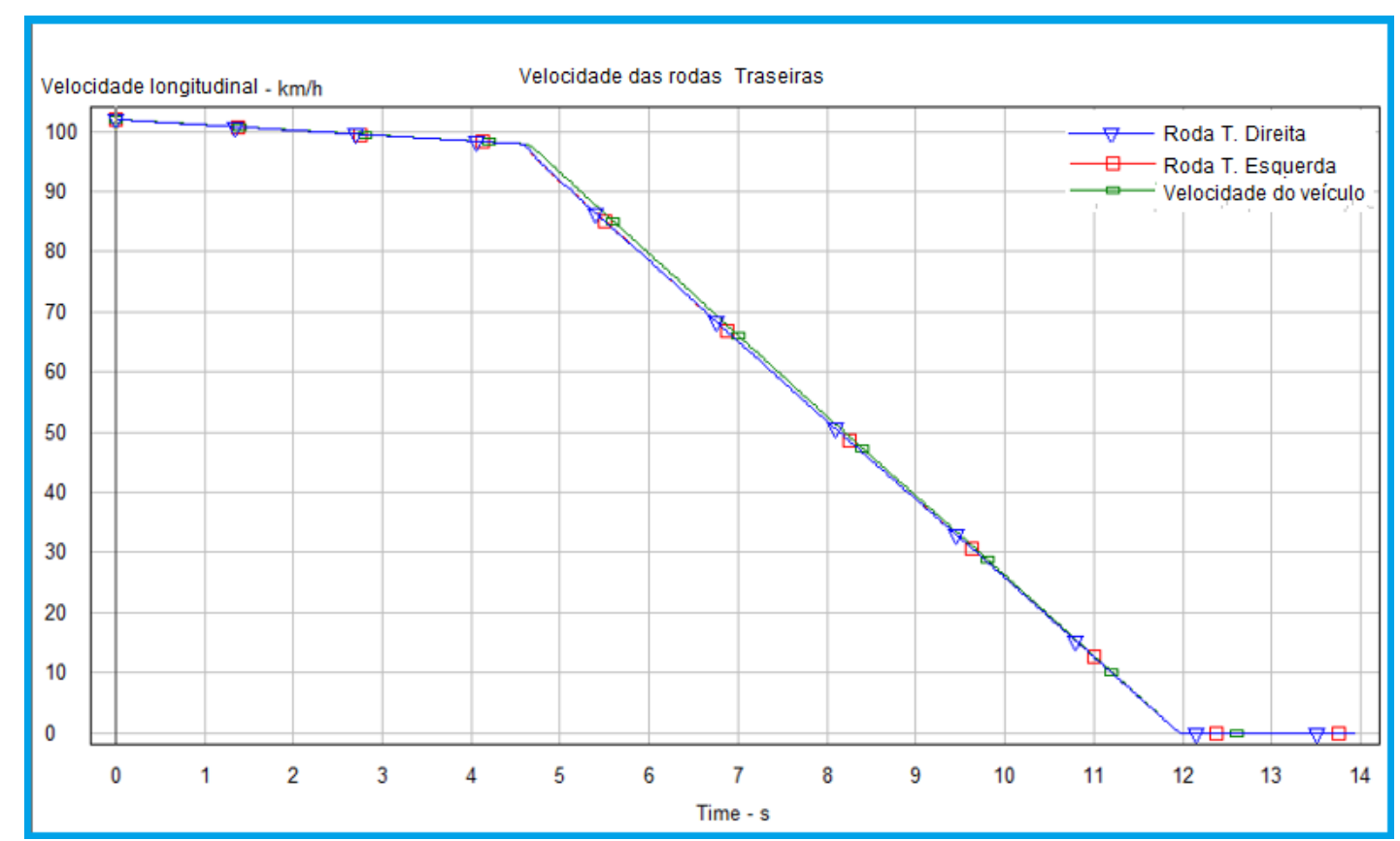

FIGURA 9. Velocidades das rodas do eixo traseiro e veloc. de referência do veículo FONTE: Software de simulação veicular

4.2. Pressão de saída da ECU ABS obtidas através dos transdutores

A figura 10 apresenta a saída de controle para a frenagem de $100 \mathrm{~km} / \mathrm{h}$ a $0 \mathrm{~km} / \mathrm{h}$. Nele é possível identificar a atuação das válvulas para controlar a pressão e consequentemente evitar o travamento das rodas. Na legenda, a pressão no cilindro de cada roda é representada por letra e número: L1 (do inglês left), pressão no cilindro da roda dianteira esquerda; R1 (do inglês right), pressão no cilindro da roda dianteira direita; L2, pressão no cilindro da roda traseira esquerda e R2 pressão no cilindro da roda traseira direita.

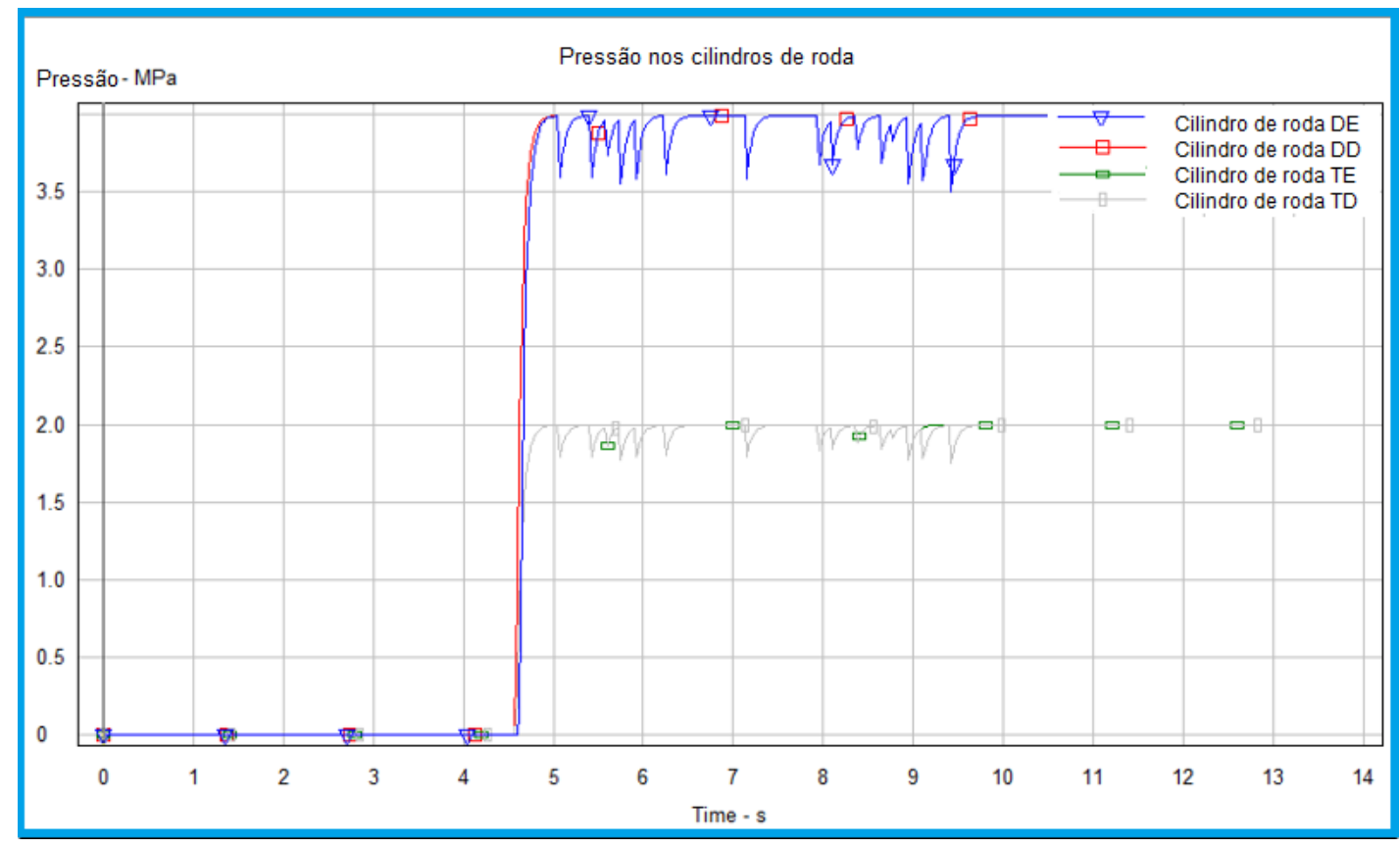

FIGURA 10. Pressão das rodas dos eixos dianteiro e traseiro 
FONTE: Software de simulação veicular

4.3. Teste de frenagem de 100 a $0 \mathrm{~km} / \mathrm{h}$ em pista com coeficiente de atrito de 0,5 sem ABS

Nas figuras 11 e 12 são apresentados os gráficos com os resultados da frenagem de $100 \mathrm{~km} / \mathrm{h}$ até $0 \mathrm{~km} / \mathrm{h}$ com coeficiente de atrito de 0,5 para os eixos dianteiro e traseiro. Neles é possível perceber que as condições de teste são as mesmas da seção 4.2 com a ressalva de que neste caso a frenagem é realizada sem o controle da ECU ABS.

Verifica-se que sem a ação de controle do ABS as rodas travam e o veículo perde a estabilidade e a dirigibilidade.

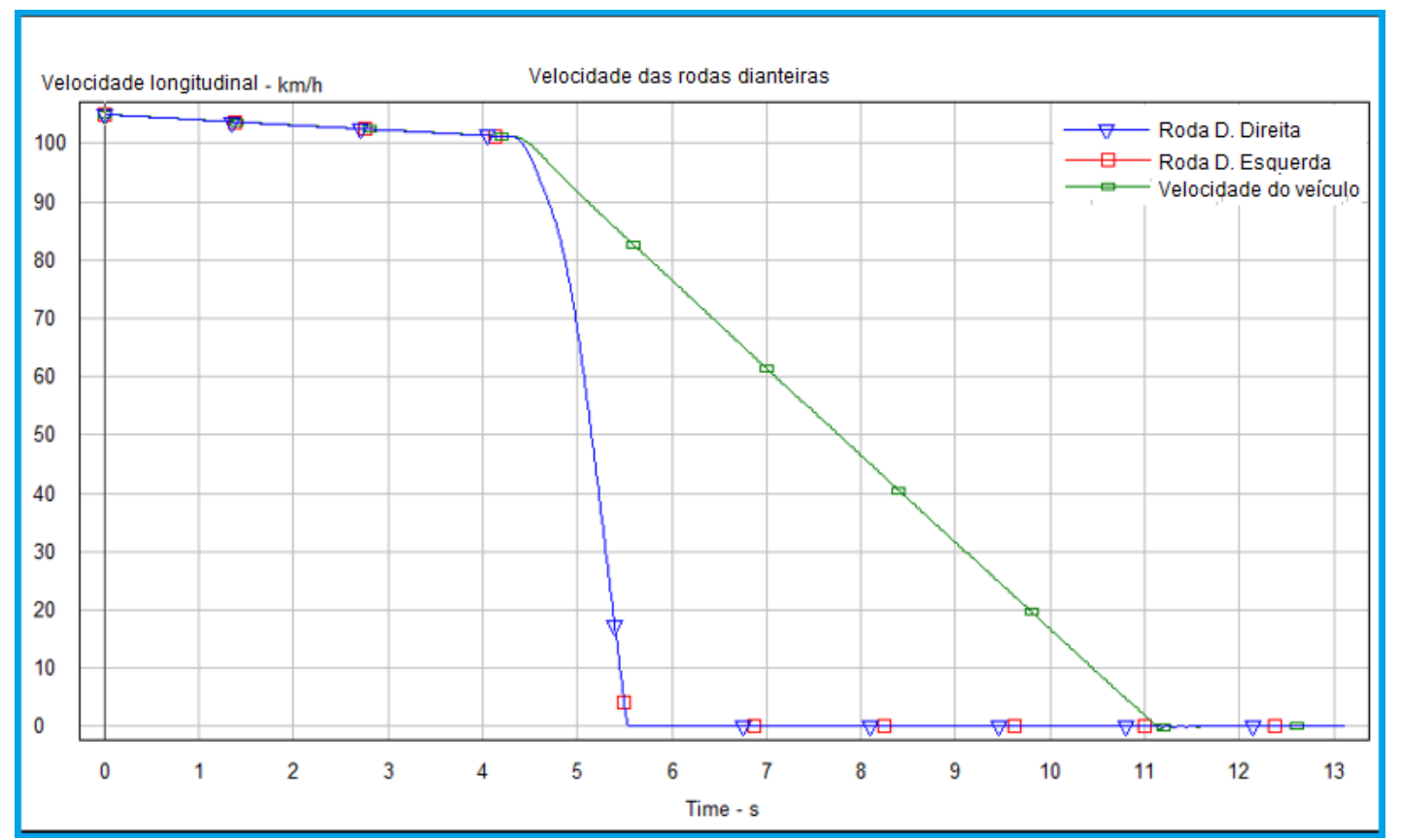

FIGURA 11. Velocidades das rodas do eixo dianteiro e velocidade de referência do veículo

FONTE: Software de simulação veicular 


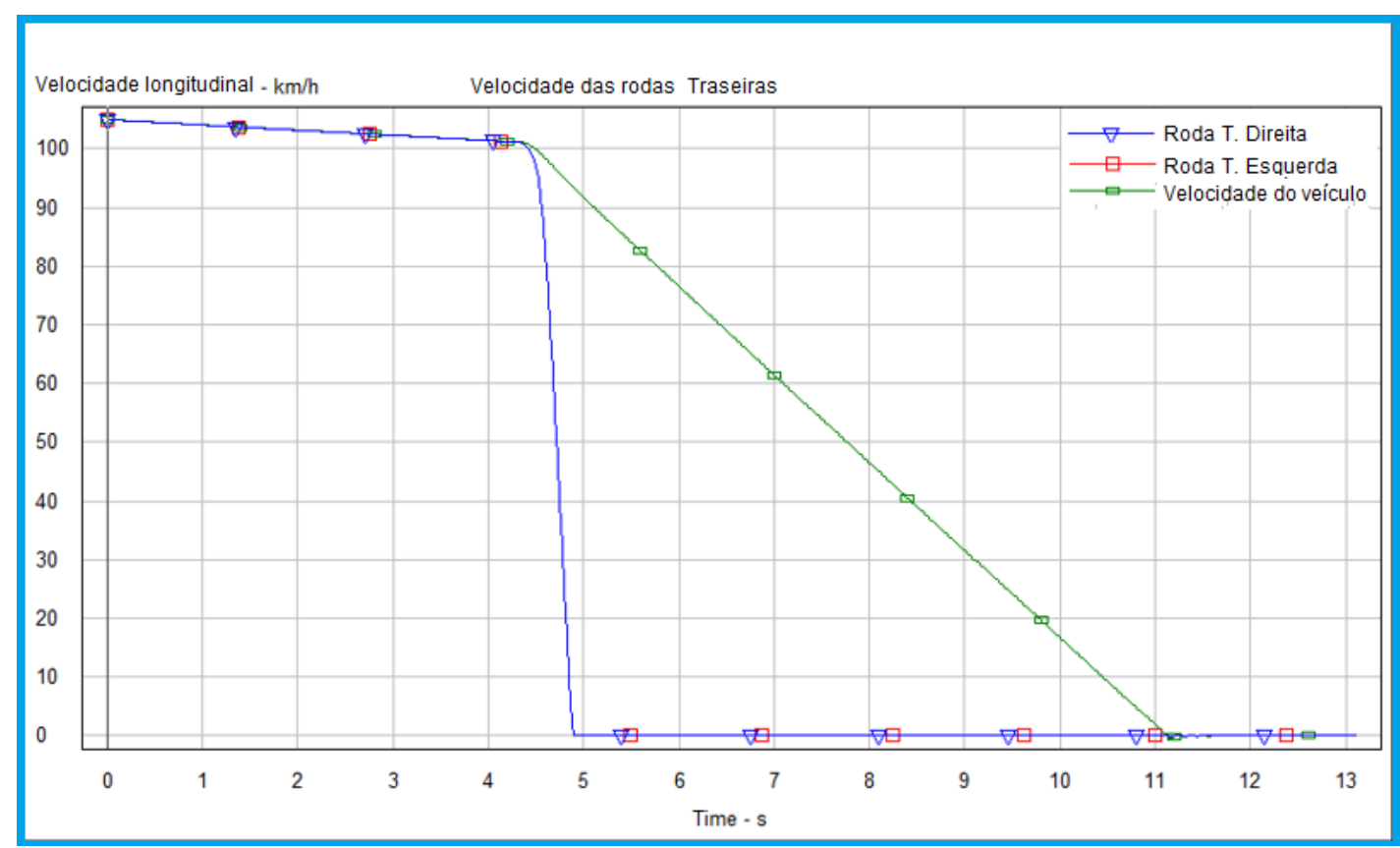

FIGURA 12. Velocidades das rodas do eixo traseiro e velocidade de referência do veículo

FONTE: Software de simulação veicular

4.4. Pressões de saída do sistema sem controle ABS

Na figura 13 é apresentado o gráfico com a pressão de saída para os cilindros de roda. Nele é possível visualizar que não há nenhuma ação de controle de ABS.

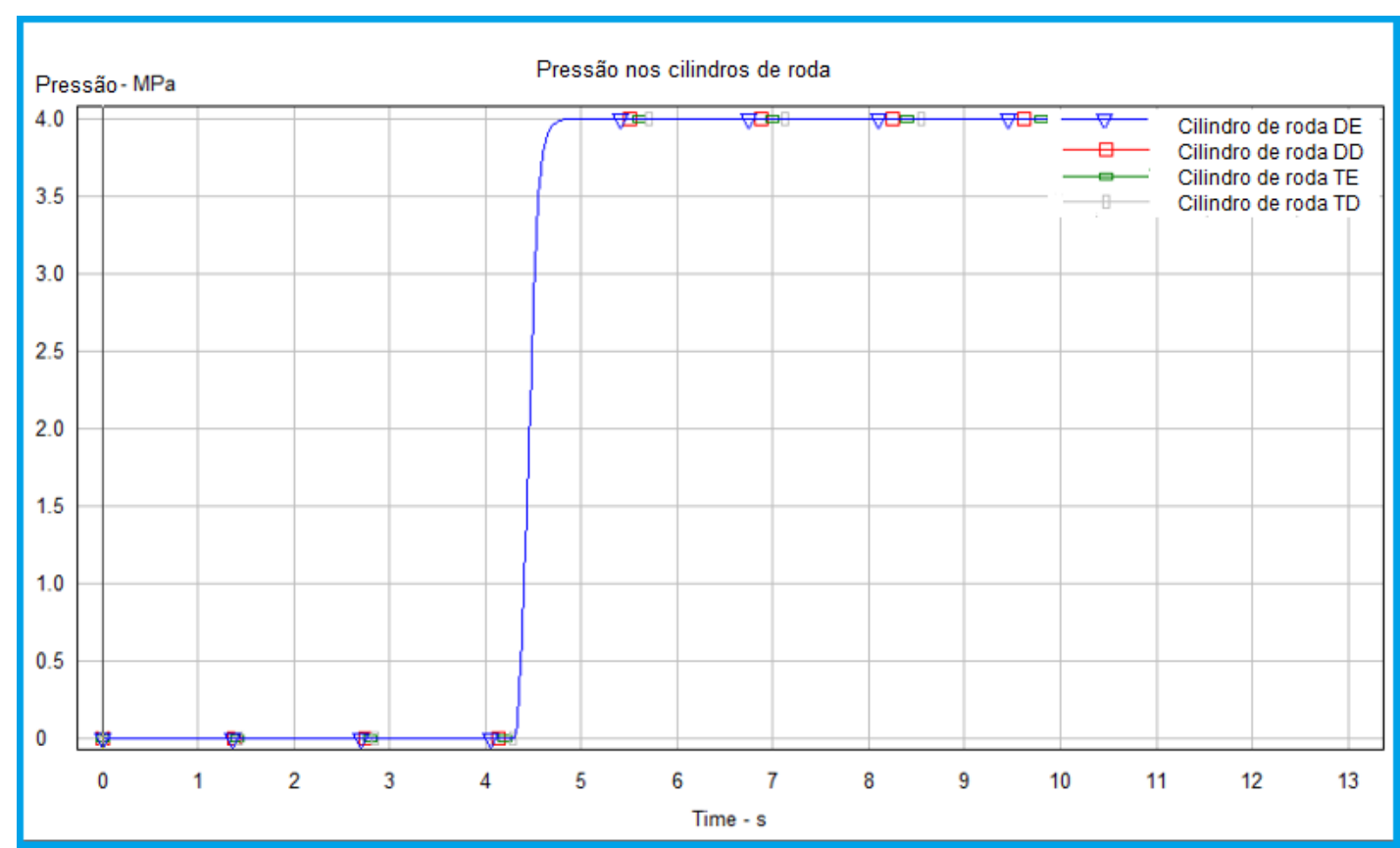

FIGURA 13. Pressões de saída do sistema sem controle ABS FONTE: Software de simulação veicular

4.5. Teste de frenagem $\mu$-split de $65 \mathrm{~km} / \mathrm{h}$ a $0 \mathrm{~km} / \mathrm{h}$ com ABS 
Nas figuras 14 e 15 são apresentados os gráficos com os resultados da frenagem de $\mu$-split de $65 \mathrm{~km} / \mathrm{h}$ até $0 \mathrm{~km} / \mathrm{h}$ em pista com coeficiente de atrito de 0,6 para o lado esquerdo e 0,85 para o lado direito, para os eixos dianteiro e traseiro. Neles é possível perceber que o controle realizado pela ECU ABS evita o travamento das rodas durante a frenagem, mantendo a estabilidade e a dirigibilidade do veículo.

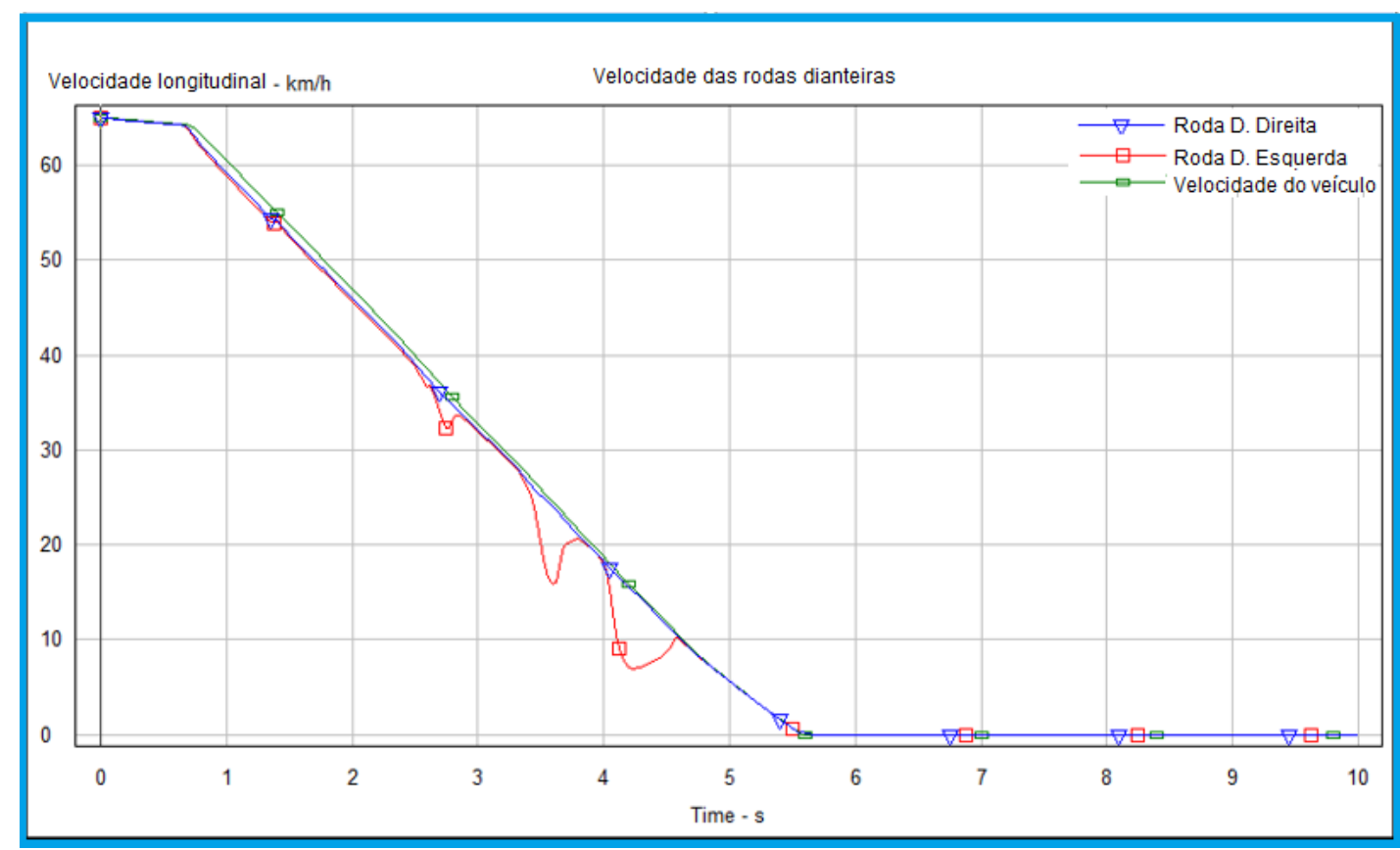

FIGURA 14. Velocidades das rodas do eixo dianteiro e velocidade de referência do veículo

FONTE: Software de simulação veicular

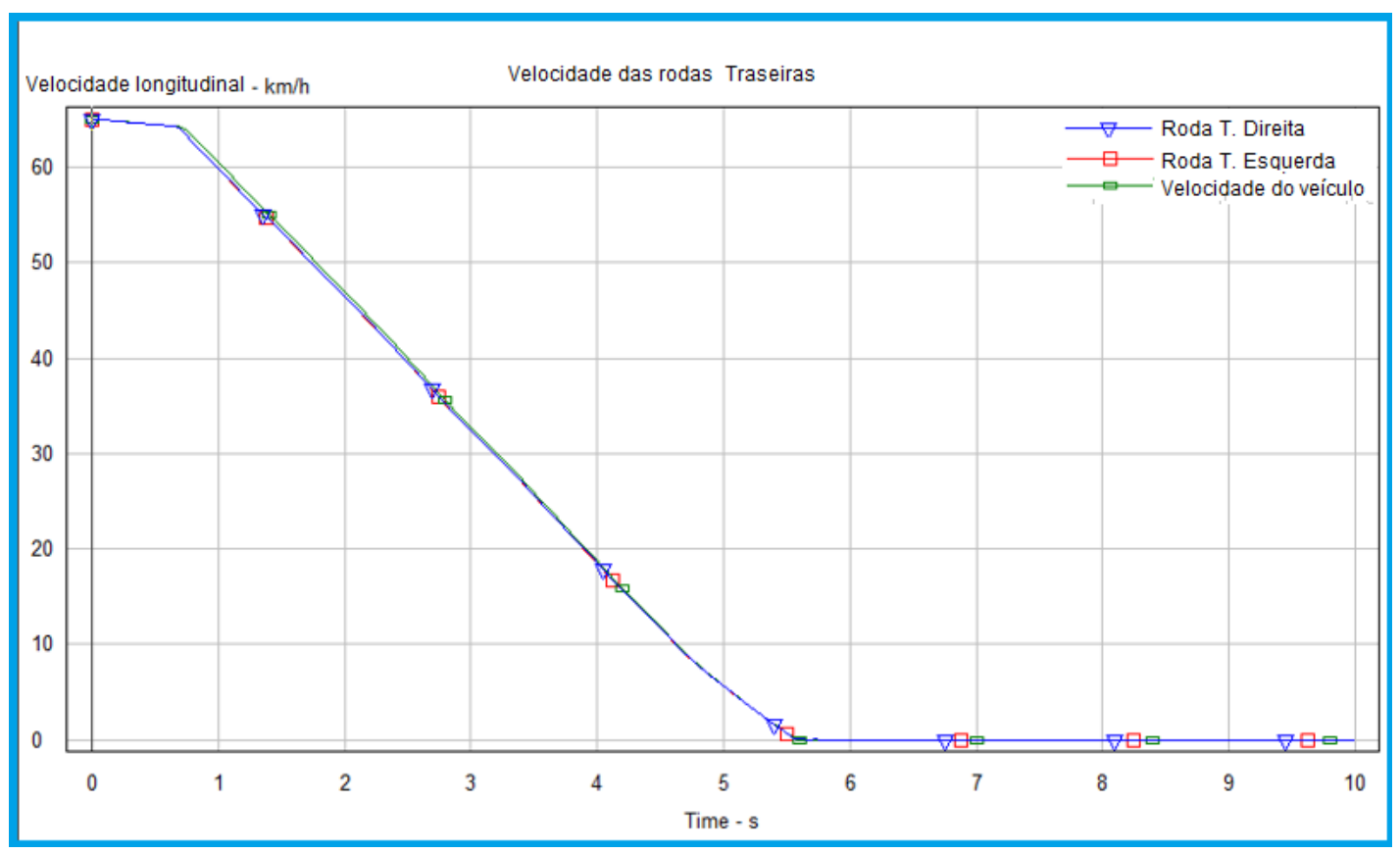

FIGURA 15. Velocidades das rodas do eixo traseiro e velocidade de referência do veículo 
FONTE: Software de simulação veicular

4.6. Pressão de saída dos cilindros de roda para frenagem $\mu$-split de $65 \mathrm{~km} / \mathrm{h}$ a $0 \mathrm{~km} / \mathrm{h}$ com ABS

A figura 16 apresenta a saída de controle para a frenagem $\mu$-split de $65 \mathrm{~km} / \mathrm{h}$ a 0 $\mathrm{km} / \mathrm{h}$.. Nele é possível identificar a atuação das válvulas para controlar a pressão e consequentemente evitar o travamento das rodas.

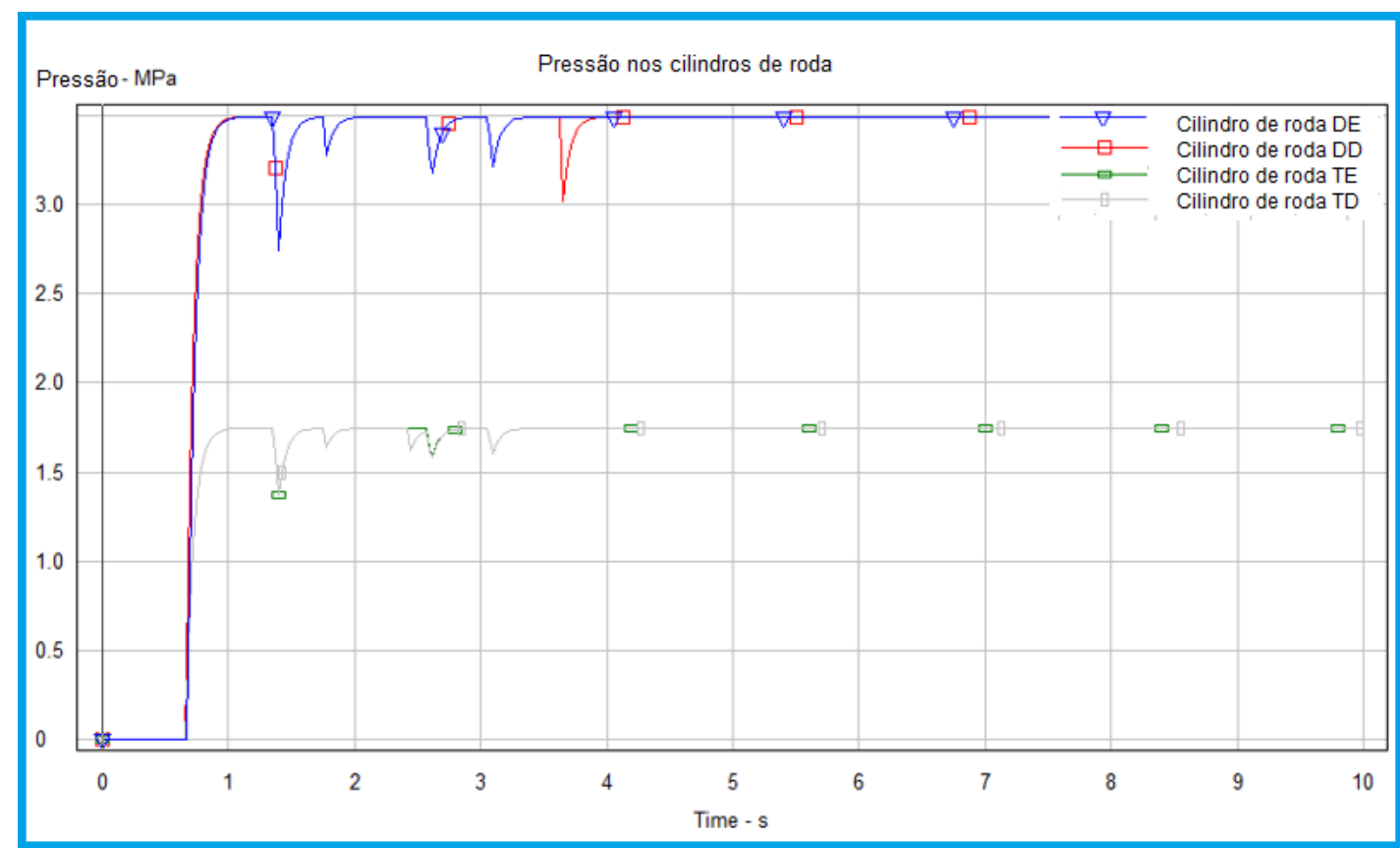

FIGURA 16. Pressão das rodas dos eixos dianteiro e traseiro FONTE: Software de simulação veicular

4.7. Teste de frenagem $\mu$-split de $65 \mathrm{~km} / \mathrm{h}$ a $0 \mathrm{~km} / \mathrm{h}$ sem controle ABS

Nas figuras 17 e 18 são aprestados os gráficos com os resultados da frenagem $\mu$-split de $65 \mathrm{~km} / \mathrm{h}$ até $0 \mathrm{~km} / \mathrm{h}$ com coeficiente de atrito de 0,6 para o lado esquerdo e 0,85 para o lado direito, para os eixos dianteiro e traseiro. Neles é possível perceber que as condições de teste são as mesmas da seção 4.6 com a ressalva de que neste caso a frenagem é realizada sem o controle da ECU ABS.

Verifica-se que sem a ação de controle do ABS as rodas travam e o veículo perde a estabilidade e a dirigibilidade. 


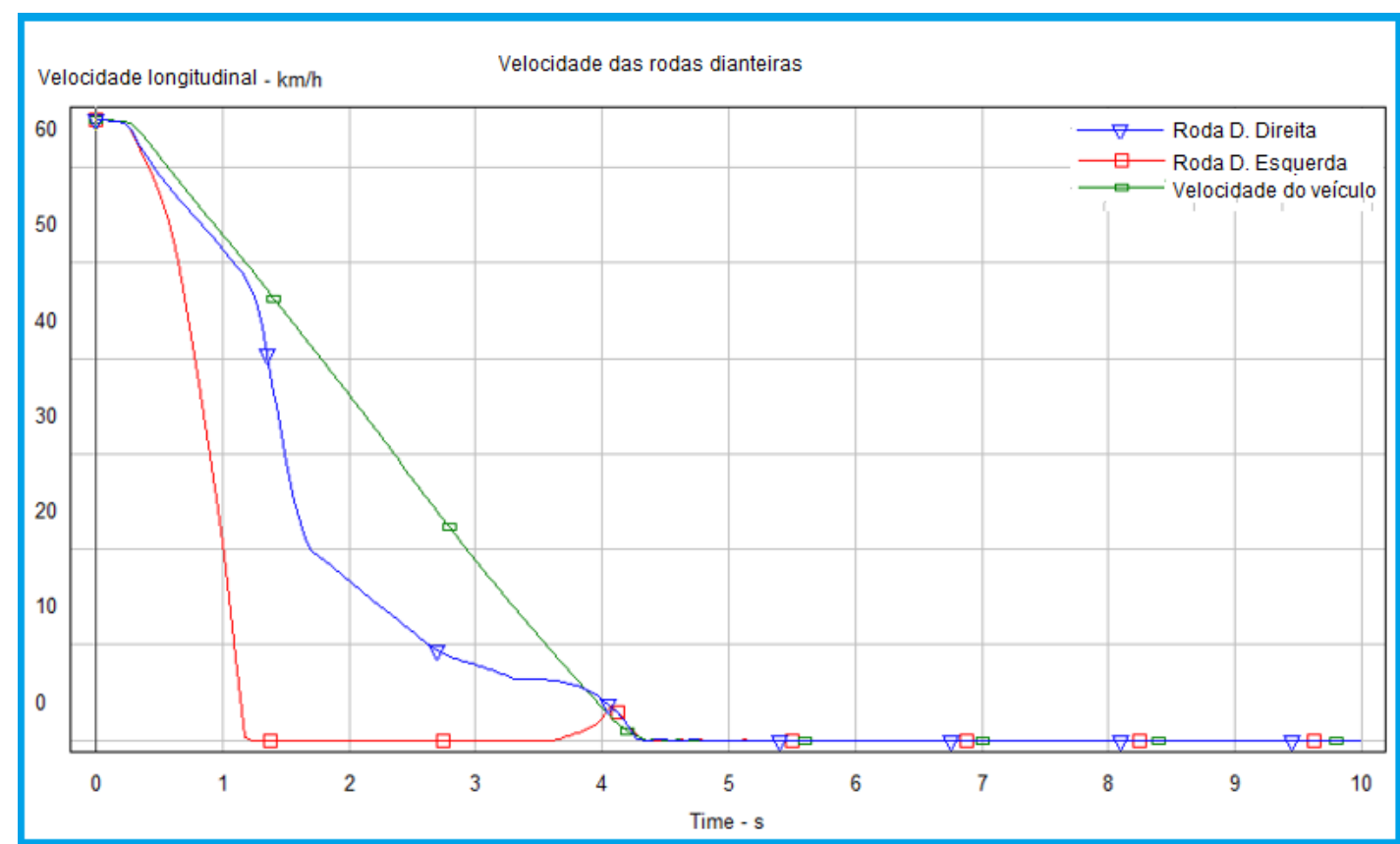

FIGURA 17. Velocidades das rodas do eixo dianteiro e velocidade de referência do veículo

FONTE: Software de simulação veicular

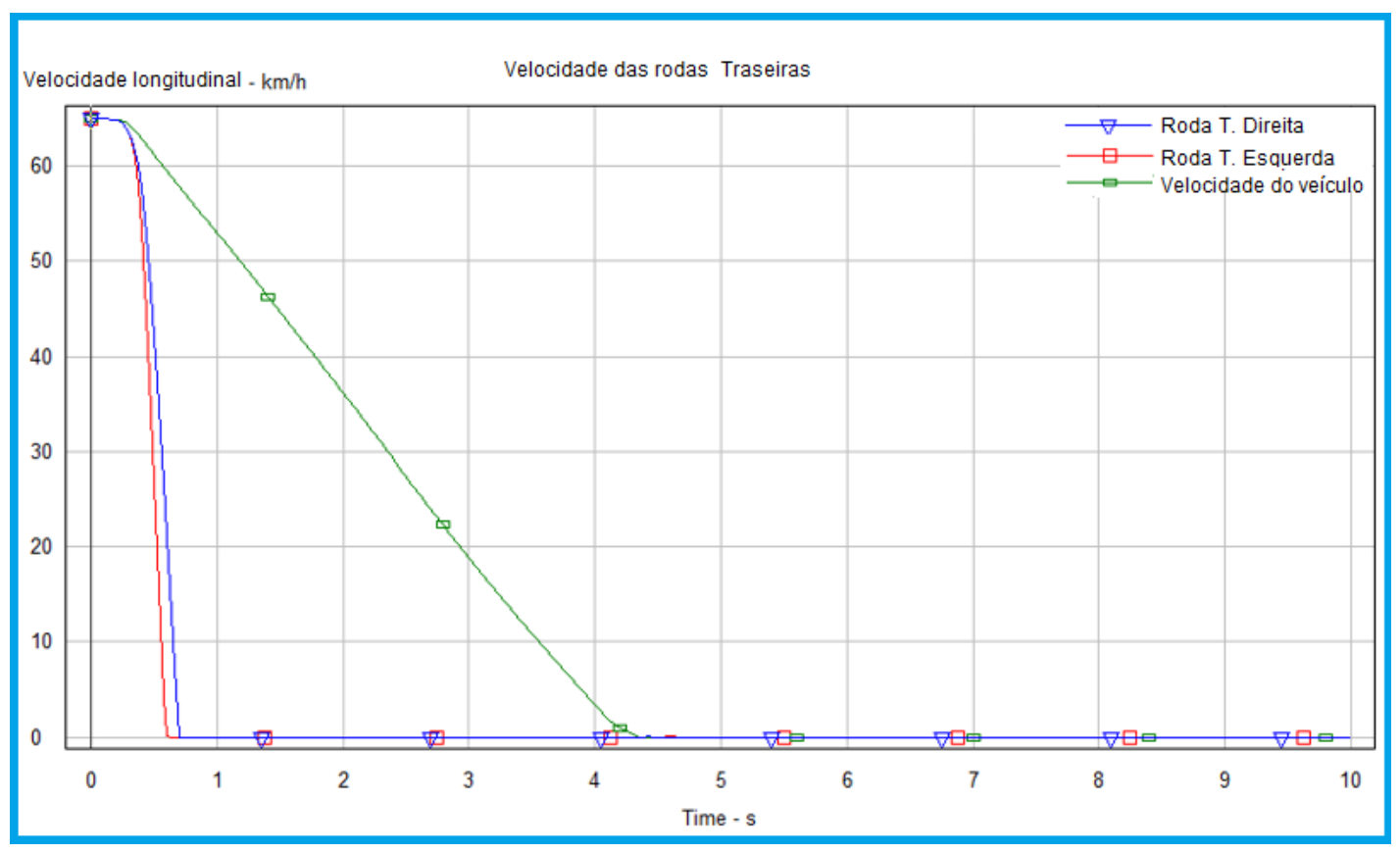

FIGURA 18. Velocidades das rodas do eixo traseiro e velocidade de referência do veículo

FONTE: Software de simulação veicular

4.8. Pressão de saída para frenagem $\mu$-split de $65 \mathrm{~km} / \mathrm{h}$ a $0 \mathrm{~km} / \mathrm{h}$ sem ABS

Na figura 19 é apresentado o gráfico com a pressão de saída para os cilindros de roda. Nele é possível visualizar que não há nenhuma ação de controle de ABS. 


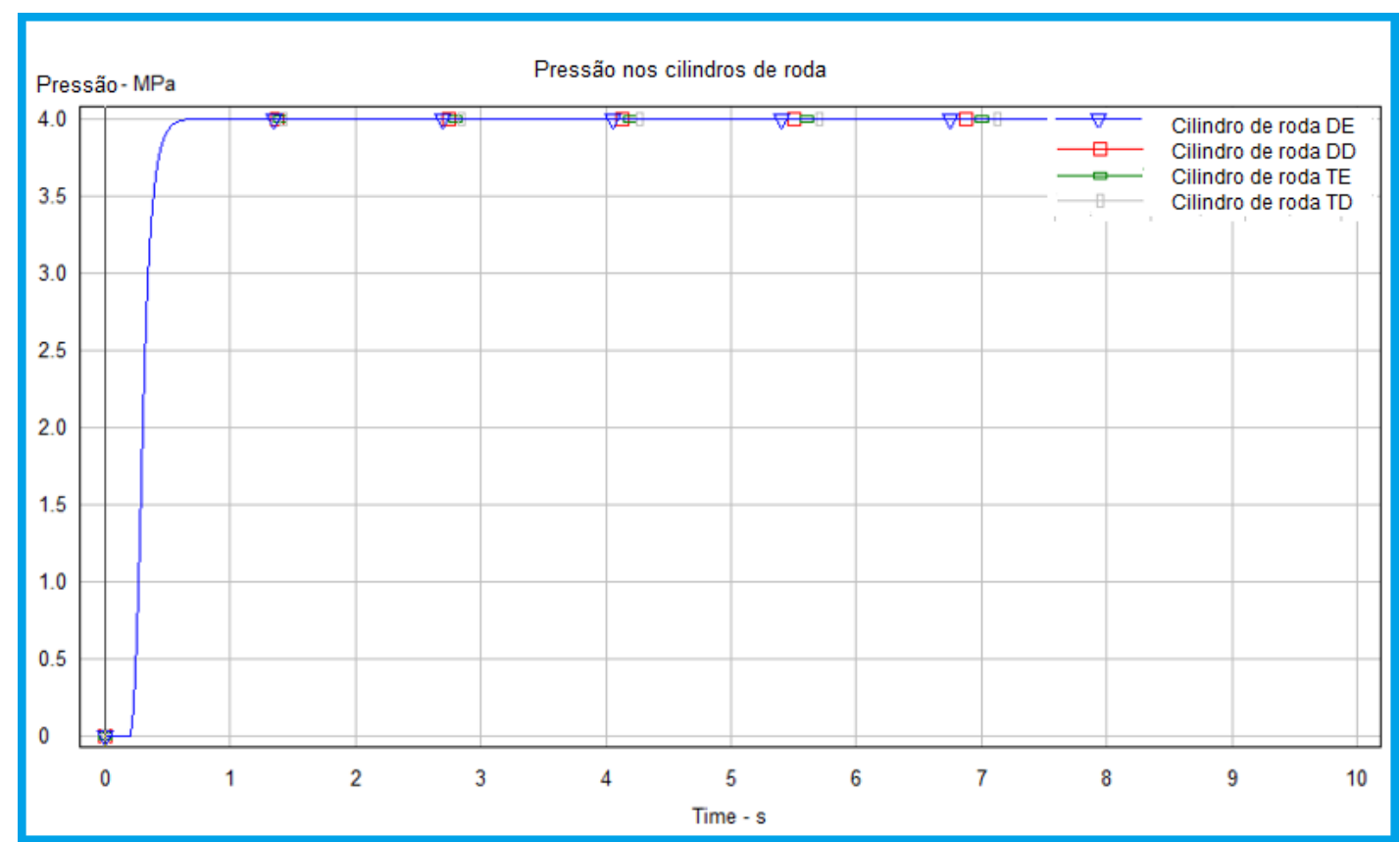

FIGURA 19. Pressão das rodas dos eixos dianteiro e traseiro

FONTE: Software de simulação veicular

\section{CONCLUSÃO}

Neste trabalho foram apresentadas as etapas de desenvolvimento de um Hardware In the Loop para freios ABS hidráulico.

Foi comprovado que a montagem do hardware com os componentes mecânicos e hidráulicos possibilitou a geração da pressão necessária para os testes através da plataforma HIL.

Foi confirmada a eficácia das velocidades simulada das rodas através de um circuito comutador de corrente lido pela ECU do ABS.

Por fim, foi apresentada a possibilidade de visualizar a ação de controle da ECU do ABS através da instalação dos transdutores de pressão nas saídas de pressão da ECU para os cilindros de freio das rodas, tendo em vista que o acesso direto às válvulas não é possível devido o corpo das válvulas ser integrado ao corpo eletrônico da ECU.

\section{REFERÊNCIAS}

[1] SANTOS, Max Mauro Dias; NEME, João Henrique Zander. A metodologia de desenvolvimento em modelos para software automotive: Hands-on. Disponível em : < sbesc.lisha.ufsc.br/sbesc2015/display2230>. Acesso em 02 de Maio de 2018.

[2] SANTOS JUNIOR, Aguinaldo Batista dos. "Desenvolvimento de plataforma de simulação hardware-in-the-loop de baixo custo", p. 302-321. In: Anais do XXIV Simpósio Internacional de Engenharia Automotiva - SIMEA 2016 [=Blucher Engineering Proceedings]. São Paulo: Blucher,2016. 
[3] HALVORSEN, Hans-Petter. Introduction to Hardware-in-the-Loop Simulation. Disponível em <http://home.hit.no/ hansha/>. Acesso em 04 de Maio de 2018.

[4] RANA, Rakesh et al. Increasing Eciency of ISO 26262 Verication and Validation by Combining Fault Injection and Mutation Testing with Model Based Development. Computer Science \& Engineering, Chalmers/ University of Gothenburg. Conference paper. Pages 1-5. 2013.

[5] CHARETTE, Robert N. This car runs on code. IEEE Spectrum, 46(3):3, 2009.

[6] X-ENGINEER. Essential aspects of the V-cycle software development process. Disponível em: <https://x-engineer.org/graduate-engineering/modeling-simulation/modelbased-design/essential-aspects-of-the-v-cycle-software-development-process/> Acessado em 05 de Maio de 2018

[7] FATHY, H. et al. Review of hardware-in-the-loop simulation and its prospects in the automotive area. Ann Arbor, v. 1001, p. 48109-2125, 2006.

[8] CONTIN, Thiago Ragozo et al. DESENVOLVIMENTO DE UM SIMULADOR PARA PERMITIR A DIRIGIBILIDADE DE UM VEÍCULO POR MEIO DE UM JOYSTICK. CIBEM 10, Porto, Portugal, 2011

[9] PRIETO, Ronaldo Deziderio; FREIOS HIDRÁULICOS: Da física básica à dinâmica veicular, do sistema convencional aos sistemas eletrônicos. Editora SENAI-SP. 2014 